\title{
Corneal Ulcer, CTCAE
}

National Cancer Institute

\section{Source}

National Cancer Institute. Corneal Ulcer, CT CAE. NCI Thesaurus. Code C143387.

A disorder characterized by an area of epithelial tissue loss on the surface of the cornea.

It is associated with inflammatory cells in the cornea and anterior chamber. 